\title{
Relative amplitude index: A new tool for hemodynamic evaluation of periprosthetic regurgitation after transcatheter valve implantation
}

\author{
Anneliese Heinz, MD, ${ }^{a}$ Michael DeCillia, MS, ${ }^{a}$ Gudrun Feuchtner, MD, ${ }^{\mathrm{c}}$ Silvana Mueller, MD, ${ }^{\mathrm{b}}$ \\ Thomas Bartel, MD, ${ }^{\mathrm{b}}$ Guy Friedrich, MD, ${ }^{\mathrm{b}}$ Michael Grimm, MD, ${ }^{\mathrm{a}}$ Ludwig Ch. Mueller, MD, ${ }^{\mathrm{a}}$ and \\ Nikolaos Bonaros, $\mathrm{MD}, \mathrm{PhD}^{\mathrm{a}}$
}

\begin{abstract}
Objective: The impact of paravalvular aortic regurgitation (PAR) on hemodynamic performance after transcatheter aortic valve implantation (TAVI) remains disputable. Common parameters such as the diastolic blood pressure or the blood pressure amplitude do not provide reproducible results. The aim of our study was to evaluate the impact of PAR on hemodynamics and outcome using the relative amplitude index (RAI).
\end{abstract}

\begin{abstract}
Methods: PAR was prospectively evaluated by echocardiography before discharge in 110 patients. The RAI was calculated according to the formula: RAI $=[$ (Post-TAVI BP amplitude $) /($ Post-TAVI SBP $)-($ Pre-TAVI BP amplitude)/(Pre-TAVI SBP)] $\times 100 \%$, where BP is blood pressure and SBP is systolic blood pressure. Correlations of increased RAI with perioperative outcome were investigated and factors influencing mortality were isolated.

Results: The incidence of moderate and severe PAR after TAVI was $9 \%$ and $1 \%$, respectively. Diastolic pressure or post-TAVI amplitude did not correlate to perioperative outcome. RAI increased from 2 when PAR was $<2+$ to 7 when PAR was $\geq 2+(P=.006)$. A cut-off value of RAI $\geq 14$ was associated with increased perioperative mortality ( 29 vs $5 \% ; P=.013$ ) and acute renal injury requiring dialysis $(71 \mathrm{vs} 18 \% ; P=.001)$. RAI $\geq 14$ was also associated with higher follow-up mortality at 1 year (57 vs $16 \% ; P=.007$ ). RAI $\geq 14$ (odds ratio [OR], 3.390; 95\% confidence interval [CI], 1.6-7.194; $P=.00146)$, PAR $\geq 2+(\mathrm{OR}, 4.717 ; 95 \% \mathrm{CI}, 1.828-12.195$; $P=.00135)$, and perioperative renal replacement therapy (OR, 12.820; 95\% CI, 5.181-31.250; $P=.00031)$ were found to be independent predictors of mortality at 1 year.
\end{abstract}

Conclusions: The RAI is a useful tool to predict perioperative and 1-year outcome in patients with PAR after TAVI. (J Thorac Cardiovasc Surg 2014;147:1021-9)

Supplemental material is available online.

Surgical aortic valve replacement (AVR) is the procedure of choice for symptom reduction and improvement of survival in patients with severe aortic stenosis. ${ }^{1}$ Among high-risk surgical patients, transcatheter aortic valve implantation

\footnotetext{
From the Department of Cardiac Surgery, ${ }^{\mathrm{a}}$ Department of Cardiology, ${ }^{\mathrm{b}}$ and Department of Radiology, ${ }^{\mathrm{c}}$ Innsbruck Medical University, Innsbruck, Austria.

Disclosures: S. Müller is a stockholder of Edwards Lifesciences and has lectured for Actelion Pharmaceuticals Inc. T. Bartel has received remuneration from Edwards Lifesciences and Biosense Webster. L. Müller has acted as consultant for Edwards Lifesciences, B Braun Aesculap, and St Jude Medical, and has lectured for Edwards Lifesciences. All other authors have nothing to disclose with regard to commercial support.

Read at the 93rd Annual Meeting of The American Association for Thoracic Surgery, Minneapolis, Minnesota, May 4-8, 2013.

Received for publication May 4, 2013; revisions received Sept 4, 2013; accepted for publication Nov 8, 2013; available ahead of print Dec 16, 2013.

Address for reprints: Nikolaos Bonaros, MD, PhD, Associate Professor of Cardiac

Surgery, Innsbruck Medical University, Anichstrasse 35, A-6020 Innsbruck

(E-mail: nikolaos.bonaros@i-med.ac.at).

$0022-5223 / \$ 36.00$

Copyright (c) 2014 by The American Association for Thoracic Surgery

http://dx.doi.org/10.1016/j.jtcvs.2013.11.011
}

(TAVI) is a noninferior therapy compared with standard AVR in terms of all-cause mortality at 30 days and 1 year. In this patient cohort, 30-day mortality was low both in the AVR group $(6.5 \%)$ and the TAVI group $(3.4 \%)$ although early-generation devices were used. ${ }^{2}$ Both TAVI and AVR are associated with different periprocedural hazards, such as more frequent major vascular and neurologic complications with TAVI, as well as more major bleeding events and atrial fibrillation with surgical AVR. Increased risk for paravalvular regurgitation (PAR) has been the common denominator of all TAVI series so far. ${ }^{3}$ Although there was no difference at 30 days, 1-year mortality was significantly higher in patients with PAR $\geq 2+$, regardless of access and left ventricular function. ${ }^{4}$ The finding that PAR $\geq 2+$ is an independent predictor of midterm to long-term mortality has also been confirmed from the 2-year data of the PARTNER (Placement of AoRtic TraNscathetER Valves) trial.

To provide increased understanding of the impact of PAR on hemodynamics after TAVI, the aortic regurgitation index, defined as the ratio of the gradient between diastolic pressure in the aorta and the left ventricular end-diastolic pressure to systolic blood pressure (SBP) has been developed. This index gives additional prognostic information 


\section{Abbreviations and Acronyms \\ AVR = aortic valve replacement \\ $\mathrm{CI}=$ confidence interval \\ $\mathrm{CPB}=$ cardiopulmonary bypass \\ $\mathrm{CT}=$ computed tomography \\ $\mathrm{DBP}=$ diastolic blood pressure \\ $\mathrm{LVEF}=$ left ventricular ejection fraction \\ $\mathrm{OR}=$ odds ratio \\ PAR = paravalvular aortic regurgitation \\ RAI = relative amplitude index \\ ROC $=$ receiver operating characteristics \\ $\mathrm{SBP}=$ systolic blood pressure \\ TAVI $=$ transcatheter aortic valve implantation \\ VARC $=$ Valve Academic Research Consortium}

to the echocardiography; a value less than 25 is an independent predictor of 1-year mortality and is associated with increased rates of PAR. ${ }^{6}$ Although this was the first attempt to establish causality based on hemodynamics between PAR and long-term outcome after TAVI, the need for a detailed echocardiographic evaluation or even better invasive hemodynamic evaluation is still a limiting factor that precludes assessment and treatment in the postoperative period.

We therefore developed an index based on preoperative and post-TAVI blood pressure measurements based on the hypothesis that blood pressure amplitude increases in the presence of PAR. ${ }^{7}$ However, preoperative blood pressure amplitude should be taken into consideration because it may be associated with preexisting regurgitation of the stenotic valve ${ }^{8}$ or with the loss of the windkessel function and elasticity of the aortic wall in patients with severe atherosclerosis. ${ }^{9}$

The aim of our study was to provide a simple, easy to measure, and reproducible tool to evaluate the impact of PAR on perioperative and midterm outcome after TAVI using simple blood pressure measurements before and after the procedure and taking blood pressure amplitude into consideration.

\section{METHODS \\ Patients}

One-hundred nineteen consecutive patients with a high-grade aortic stenosis underwent TAVI between March 2008 and December 2012 and were analyzed retrospectively. The study was approved by the local Ethical Committee and each patient gave informed consent.

Aortic stenosis was diagnosed by transthoracic echocardiography. Indications for surgery were based on the transthoracic echocardiography results and symptoms. A preoperative computed tomography (CT) scan with 128-slice, high-pitch, dual-source, prospective CT angiography was performed for preoperative evaluation.

A previous cardiac intervention was noted in 51 patients (43\%). Almost one-third of the patients $(\mathrm{n}=32,27 \%)$ had previous cardiac surgery at a median of 10 years before TAVI (range, 5 to 19 years). These previous procedures included aortic valve surgery $(n=2)$, mitral valve surgery $(\mathrm{n}=2)$, aortic and tricuspid valve surgery $(\mathrm{n}=1)$, and bypass surgery $(\mathrm{n}=27)$. In addition, percutaneous coronary interventions were performed in 23 patients $(20 \%)$ at a median of 2 years before TAVI. In 5 patients $(4 \%)$, a previous balloon valvuloplasty was performed at a median of 7 months before TAVI.

Perioperative complications, such as mortality, cardiac, lung, cerebrovascular, or renal dysfunction, implantation of a second valve caused by prosthesis migration and PAR, as well as long-term outcome regarding survival and late prosthesis dysfunction were analyzed according to the Valve Academic Research Consortium (VARC)-2 criteria. $^{10}$

Perioperative mortality was defined as mortality within 30 days. Longterm mortality was defined as death thereafter. The follow-up period was 2 to 1721 days (median, 377 days) and was $100 \%$ complete including clinical and echocardiographic examinations. Examination visits were standardized at 30 days, 6 months, 12 months, and thereafter yearly after TAVI. Procedural outcome was analyzed according to the VARC- 2 criteria regarding device success, early safety, clinical efficacy, and time-related valve safety. Renal impairment was analyzed according to the Acute Kidney Injury Network system. ${ }^{10}$

PAR was prospectively evaluated by echocardiography during TAVI and before discharge. Echocardiographic evaluation was based on perioperative transesophageal or intracardiac echocardiography according to the recommendations of the European Association of Echocardiography. ${ }^{11}$ The relative amplitude index (RAI) was retrospectively calculated according to the following formula:

RAI $=\left(\frac{\text { Post-TAVI BP amplitude }}{\text { Post-TAVI SBP }}-\frac{\text { Pre-TAVI BP amplitude }}{\text { Pre-TAVI SBP }}\right) \times 100 \%$

where BP is blood pressure and SBP is systolic blood pressure.

In our study, blood pressure was measured intraoperatively using arterial pressure. Preimplantation values were the average of at least 3 values between skin cut and balloon valvuloplasty and postimplantation values were the average of at least 3 values between valve implantation and skin suture. To evaluate the potential effect of continuous invasive blood pressure measurements on RAI, we also analyzed noninvasive blood pressure measurements in 88 patients. These included preoperative measurements at admission and the median of 5 postoperative measurements after extubation, without inotropes, and in a comparable volume status until discharge. All measurements included were performed under stable hemodynamic and rhythm conditions.

The formula was created and calculated by using intraoperative blood pressure measurements, which were collected independently from the clinical outcome. In addition to the collection of intraoperative blood pressure data, the clinical outcome and follow-up data were collected separately by 3 different investigators after Ethical Committee approval. The statistical analysis was undertaken after completion of the data set. Therefore, there is no observer bias at any time in the study and the results of the RAI calculations could not be influenced by the clinical data.

\section{Surgical Technique}

All TAVI procedures were evaluated, indicated, and performed by a heart team. During TAVI, 1 experienced cardioanesthesiologist and 1 perfusionist were always present in the operating room. Apart from the first 9 procedures, which were performed in a catheterization laboratory, all other interventions took place in the cardiac operating room with cardiopulmonary bypass $(\mathrm{CPB})$ on standby using a new generation mobile C-arm (OEC 9800, Ziehm RFD, Philips Veradius, Siemens Arcadis). Each patient underwent general anesthesia and was set up with an arterial blood pressure line, intracardial echocardiography or transesophageal echocardiography, and a submerged temporal pacemaker. The surgical approach for TAVI was always performed by a cardiac surgeon as planned after a preoperative CT scan: transfemoral approach with a 3 to $4 \mathrm{~cm}$ incision in the groin and femoral artery preparation; transapical approach with 
a 5 to $6 \mathrm{~cm}$ incision in the fifth or sixth intercostal space as an anterolateral thoracotomy; transaxillary approach with a 3 to $4 \mathrm{~cm}$ incision below the clavicle; and transaortal approach with a 5 to $6 \mathrm{~cm}$ incision and upper hemisternotomy in the second intercostal space.

\section{Statistical Analysis}

Continuous variables were expressed as the median and range, categorical variables as percentages. Continuous variables were analyzed by the Mann-Whitney $U$ test, categorical variables were tested for differences using the $\chi^{2}$ test. Estimates of survival and the incidence of valve-related complications were calculated using Kaplan-Meier graphs and statistical differences were analyzed by the Wilcoxon method. Statistical analysis was performed using SPSS statistical software 19.0 (SPSS Inc, Chicago, Ill). The cut-off value for RAI, over which perioperative mortality reached statistical significance, was evaluated by receiver operating characteristics (ROC) analysis (Figure E1). Patients with an RAI above the cut-off value were then compared with patients with an RAI below the cut-off value in terms of perioperative and postoperative outcome. Dependent and independent factors for perioperative and follow-up mortality were isolated using Cox regression analysis.

\section{RESULTS}

Of the 119 patients who were initially included for intentto-treat analysis, 110 underwent the procedure as planned and were included in our study. The reasons for exclusion were uncompleted TAVI because of narrow femoral vessels (only balloon valvuloplasty performed in 2 patients), conversion to conventional AVR in 5 patients (ventricular perforation in 2 patient, annulus rupture in 1 patient, valve migration in the left ventricular outflow tract in 1 patient, and irreversible crash of an old generation mobile C-arm in 1 patient), and lost to follow-up (2 patients). Patients with uncompleted TAVI and conversion to conventional AVR were excluded because no relevant postprocedural RAI could be calculated. Patients lost to follow-up were also excluded to avoid incomplete reporting of the results.

The patients included had a median age of 83 years (range, 58-97 years), 51 were male (46\%), and the median EuroSCORE II was 10 (range, 2-40). Demographics, preoperative risk factors, and details on access site are presented in Table 1.

\section{Intraoperative Complications}

Besides conversion to AVR, an unplanned use of $\mathrm{CPB}$ was necessary in a further 6 patients. In 1 patient, conversion to full sternotomy was needed because of apex perforation. In 2 patients, valve malposition led to a second valve implantation. In 3 patients, the TAVI procedure was a valve-in-valve deployment. There was no case of coronary obstruction, ventricular septum perforation, or mitral valve damage or dysfunction. The device success rate according to the VARC- 2 criteria ${ }^{10}$ was $98 \%(n=108)$.

\section{Perioperative Results}

The perioperative mortality was $6 \%(n=7)$. These patients died of multiorgan failure and low output syndrome
TABLE 1. Patient demographics, preoperative risk factors, and access site

\begin{tabular}{|c|c|c|}
\hline & $\begin{array}{l}\text { Number or value } \\
\qquad(\mathbf{N}=110)\end{array}$ & Range or $\%$ \\
\hline Age (y) & 83 & $58-97$ \\
\hline $\operatorname{Sex}(M / F)$ & $51 / 59$ & $46 / 54$ \\
\hline Body mass index $\left(\mathrm{kg} / \mathrm{m}^{2}\right)$ & 25 & $18-37$ \\
\hline EuroSCORE II & 10 & $2-40$ \\
\hline Left ventricular ejection fraction $(\%)$ & 50 & $11-73$ \\
\hline Arterial hypertension & 101 & 92 \\
\hline Atrial fibrillation & 39 & 36 \\
\hline Myocardial infarction & 9 & 8 \\
\hline Pulmonary hypertension & 35 & 32 \\
\hline Chronic obstructive pulmonary disease & 24 & 22 \\
\hline Cerebrovascular disease & 31 & 28 \\
\hline Stroke & 16 & 15 \\
\hline Renal impairment & 9 & 8 \\
\hline Previous dialysis & 3 & 3 \\
\hline Previous cardiac surgery & 29 & 26 \\
\hline $\begin{array}{l}\text { Previous percutaneous coronary } \\
\text { intervention }\end{array}$ & 24 & 22 \\
\hline \multicolumn{3}{|l|}{ Access site } \\
\hline Transfemoral & 49 & 45 \\
\hline Transapical & 48 & 44 \\
\hline Transaxillar & 5 & 4 \\
\hline Transaortic & 8 & 7 \\
\hline Balloon expanded & 104 & 95 \\
\hline Self-expanded & 6 & 5 \\
\hline Follow-up period (d) & 377 & $2-1721$ \\
\hline
\end{tabular}

$(\mathrm{n}=5)$, respiratory failure $(\mathrm{n}=1)$, and terminal renal failure $(n=1)$ between postoperative day 2 and 24. Perioperative results are summarized in Table 2. Intensive care unit stay was 24 hours (range, 2-1027 hours). Early safety and clinical efficacy according to the VARC-2 criteria were fulfilled by 78 patients $(71 \%)$ and 101 patients $(92 \%)$, respectively. PAR $\geq 2+$ was detected in 11 patients $(10 \%)$. None of the patients included in the series had relevant central regurgitation. This was confirmed in 3 different projections using echocardiography. An RAI value between -13 and $+23 \%$ (mean $+3 \%$ ) was calculated after taking into consideration perioperative blood pressure measurements.

The RAI increased from $2(-32$ to $+23 \%)$ when PAR was $<2+$ to $7(-3$ to $+17 \%)$ when PAR was $\geq 2+$ $(P=.006)$ (Figure E2, $A)$. In contrast, neither the absolute blood pressure amplitude (Figure E2, B) nor the absolute diastolic pressure amplitude (Figure E2, $C$ ) differed in patients with PAR $<2+$ versus patients with PAR $\geq 2+(65$ $\mathrm{mm} \mathrm{Hg}$ [range, $40-85 \mathrm{~mm} \mathrm{Hg}$ ] vs $55 \mathrm{~mm} \mathrm{Hg}$ [range, $30-$ $75 \mathrm{~mm} \mathrm{Hg}$ ], respectively; $P=.932$ ). A cut-off value for the RAI of 14 was calculated by ROC analysis $(P=.035)$ and patients with an RAI $\geq 14$ had increased perioperative ( 29 vs $5 \% ; P=.013)$ and long-term mortality $(71 \%$ vs $25 \% ; P=.007)$ compared with patients with an RAI $<14$ 
TABLE 2. Perioperative and midterm results after transcatheter aortic valve implantation stratified by RAI

\begin{tabular}{|c|c|c|c|c|c|c|c|}
\hline & \multirow[b]{2}{*}{$\begin{array}{c}\text { All patients } \\
(\mathbf{N}=\mathbf{1 1 0}), \mathbf{n}(\%)\end{array}$} & \multicolumn{3}{|c|}{ Perioperative results } & \multicolumn{3}{|c|}{ Follow-up results at 1 y } \\
\hline & & $\begin{array}{c}\text { RAI }<14 \\
(\mathbf{n}=\mathbf{1 0 3}), \mathbf{n}(\%)\end{array}$ & $\begin{array}{c}\text { RAI } \geq 14 \\
(\mathbf{n}=7), \mathbf{n}(\%)\end{array}$ & $\begin{array}{c}P \\
\text { value }\end{array}$ & $\begin{array}{c}\text { RAI }<\mathbf{1 4} \\
(\mathbf{n}=\mathbf{1 0 3}), \mathbf{n}(\%)\end{array}$ & $\begin{array}{c}\text { RAI } \geq 14 \\
(\mathbf{n}=7), \mathbf{n}(\%)\end{array}$ & $\begin{array}{c}P \\
\text { value }\end{array}$ \\
\hline 30-d mortality & $7(6)$ & $5(5)$ & $2(29)$ & .013 & & & \\
\hline Overall mortality & $30(27)$ & & & & $16(16)$ & $4(57)$ & .007 \\
\hline Reoperation due to bleeding & $4(4)$ & & & & & & \\
\hline Major vascular complication & $5(5)$ & & & & & & \\
\hline Pacemaker implantation & $4(4)$ & & & & & & \\
\hline \multicolumn{8}{|l|}{ Paravalvular aortic regurgitation } \\
\hline None or trace & $61(56)$ & $59(57)$ & $2(29)$ & .067 & & & \\
\hline Mild & $38(35)$ & $35(34)$ & $3(43)$ & .633 & & & \\
\hline Moderate & $10(9)$ & $9(9)$ & $1(13)$ & .621 & & & \\
\hline Severe & $1(1)$ & $0(0)$ & $1(14)$ & $<.001$ & & & \\
\hline Perioperative respiratory failure & $9(8)$ & $8(8)$ & $1(14)$ & .460 & & & \\
\hline $\begin{array}{l}\text { Perioperative AKI requiring } \\
\text { hemofiltration }\end{array}$ & $23(21)$ & $18(18)$ & $5(71)$ & .001 & $3(3)$ & $1(20)$ & .06 \\
\hline AKI Stage 1 & $35(32)$ & $32(31)$ & $3(43)$ & .517 & & & \\
\hline AKI Stage 2 & $17(16)$ & $15(15)$ & $2(29)$ & .321 & & & \\
\hline AKI Stage 3 & $9(8)$ & 7 (7) & $2(29)$ & .101 & $7(7)$ & $0(0)$ & .531 \\
\hline Stroke & & $2(2)$ & $0(0)$ & .710 & $5(5)$ & $0(0)$ & 601 \\
\hline Myocardial infarction & $1(1)$ & 0 & 0 & & $1(1)$ & $0(0)$ & .819 \\
\hline Device success & $108(98)$ & $2(2)$ & $0(0)$ & .710 & & & \\
\hline \multicolumn{8}{|l|}{ Valve deterioration } \\
\hline Endocarditis & $1(1)$ & & & & $1(1)$ & $0(0)$ & .819 \\
\hline Dysfunction & $10(9)$ & & & & $8(8)$ & $2(29)$ & .068 \\
\hline Degeneration & 0 & & & & 0 & 0 & \\
\hline Rehospitalization for cardiac reasons & $17(16)$ & & & & $15(15)$ & $2(29)$ & 147 \\
\hline
\end{tabular}

$R A I$, Relative amplitude index; $A K I$, acute kidney injury.

(Table 2). All common preoperative risk factors showed no significant difference between RAI $<14$ and RAI $\geq 14$.

To evaluate the effect of blood pressure measurements on RAI, we retrospectively compared invasive and noninvasive techniques. We found a significant correlation (Spearman rho $=0.673, P=.031$ ) between the intraoperative RAI based on invasive blood pressure measurements and the postoperative RAI based on noninvasive measurements. Similar to the invasive measurements, there was a higher incidence of perioperative $(P=.024)$ and 1-year mortality $(P=.014)$ among patients with RAI $\geq 14$ measured by noninvasive means. We also performed additional calculations to examine the effect of postoperative RAI based on noninvasive measurements on 30-day and follow-up mortality. There was a significantly higher incidence of both perioperative and follow-up mortality in patients with RAI $>14$ (data not shown).

$\mathrm{RAI} \geq 14$ was a significant predictor for 30 -day (odds ratio $[\mathrm{OR}], 7.840 ; 95 \%$ confidence interval $[\mathrm{CI}], 1.208$ $50.863 ; P=.013)$ and follow-up mortality (OR, 7.8; $95 \%$ CI, 1.424-42.721; $P=.007)$ in the univariate analysis (Table 3). PAR $\geq 2+$ was not significant for perioperative mortality (OR, 4.178; 95\% CI, 0.707-24.692; $P=.091$ ) but was significant for follow-up mortality (OR, 7.783; 95\% CI, 1.554-21.518; $P=.004)$. RAI (OR, 3.390; 95\%
CI, 1.6-7.194; $P=.00146)$, PAR $\geq 2+(\mathrm{OR}, 4.717 ; 95 \%$ CI, 1.828-12.195; $P=.00135)$, and perioperative renal replacement therapy (OR, 12.820; 95\% CI, 5.181-31.250; $P=.00031)$ were independent predictors of mortality in the follow-up period.

\section{Long-Term Results}

Survival at 1,3 , and 4 years was $82 \%, 58 \%$, and $40 \%$, respectively (Figure 1). At a median of 377 days of follow-up, 30 patients $(27 \%)$ died. Complications in the follow-up period occurred in 26 patients (Table 2). Perioperative and long-term results stratified by mortality and RAI are shown in Table 3 and Figure 2. There was no valve thrombosis or reoperation of the aortic valve after TAVI. Time-related valve safety during follow-up according to the VARC- 2 criteria was fulfilled by 95 patients $(86 \%)$.

\section{DISCUSSION}

In this study, we aimed for the first time to evaluate an easy to measure, reproducible, and inexpensive index based on blood pressure amplitude as a predictive factor for perioperative and midterm mortality. In most cases with moderate or severe PAR, angiographic or, even better, echocardiographic evaluation is easy to perform with reliable results. In our hands, most PAR is still mild or mild 


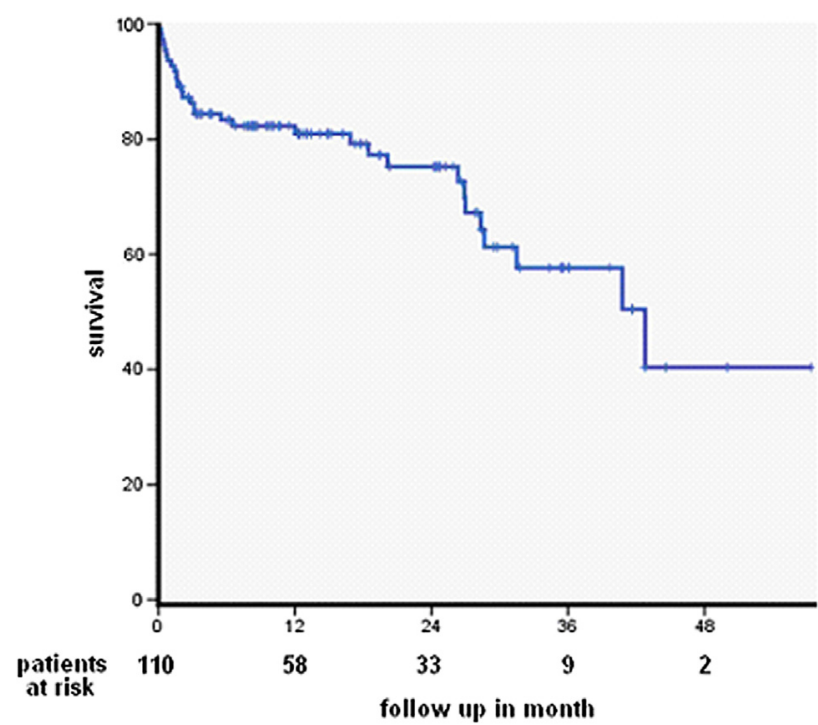

FIGURE 1. Kaplan-Meier graph for survival in the whole study population.

to moderate. It is therefore obvious that an additional criterion is needed to identify patients who would benefit from postdilation and to what extent this dilation should be performed to avoid dilatation-associated complications (embolism, aortic rupture, and aortic dissection). Taking into consideration these points, we consider RAI to be a complementary index to the echocardiographic or angiographic evaluation of PAR.

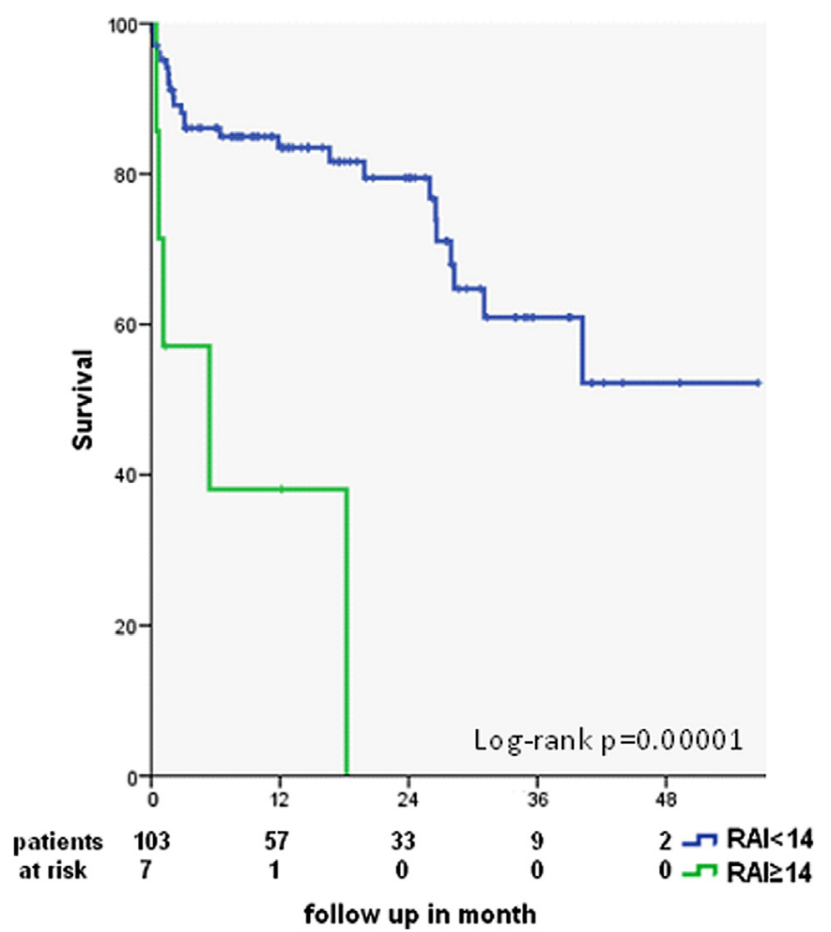

FIGURE 2. Kaplan-Meier graph for survival for RAI $<14$ versus $\geq 14$. $R A I$, Relative amplitude index.
Our results underline the major impact of PAR on hemodynamics after transcatheter treatment of severe aortic stenosis. The results show that hemodynamic alterations have an impact on blood pressure amplitude and on the RAI. This index is defined as the difference in the ratio of preoperative and postoperative blood pressure amplitude divided by the concomitant SBP. In our hands, RAI has been found to correlate with the presence of hemodynamically relevant PAR (PAR $\geq 2+$ ) and with 30-day and midterm mortality after TAVI. RAI levels $\geq 14$ have also been shown to be an independent predictor of 1-year mortality. These findings give this easy to calculate and reproducible index increasing importance for predicting outcome after TAVI.

With regard to the clinical outcome of this series, we demonstrated equivalent results to those reported in major TAVI registries (German Aortic Valve Registry [GARY] and registries in the United Kingdom, Italy, and France). Our patient series was mainly treated with balloonexpandable valves and the results were in line with the existing literature regarding perioperative and long-term mortality, incidence of stroke, need for pacemaker implantation, and myocardial infarction. ${ }^{12-14}$ There is a slight discrepancy in the literature concerning the effect of the valve implanted on the incidence of PAR. The UK and German registries in contrast to the French and Italian registries demonstrated an increased rate of PAR in selfexpandable valves. We observed an incidence of clinically relevant PAR of $10 \%$, which is in line with the results reported for balloon-expandable valves. Also the results of valve-in-valve procedures were highly satisfactory in our study with a procedural success rate of $100 \%$ and low PAR, making this a safe and feasible alternative to treat high-risk patients with failing bioprostheses. ${ }^{15}$

The impact of PAR as well as the detailed pathophysiologic alterations associated with the sudden change from pressure to volume overload is still under investigation. ${ }^{8}$ A possible approach for chronic AVR could be the correlation between the decrease in diastolic blood pressure (DBP) and the increase in SBP. ${ }^{16}$ On the contrary, in acute aortic regurgitation the left ventricle fails to increase the stroke volume, which results in increased left ventricular enddiastolic pressure and consequently pulmonary edema and decreased SBP. ${ }^{8}$ The combination of decreased DBP as a result of aortic regurgitation and decreased SBP as a consequence of acute volume overload induces end-organ damage including myocardial and renal ischemia, as well as pulmonary complications. According to our results, the evaluation of postoperative DBP or blood pressure amplitude was not associated with PAR or with periprocedural or long-term complications. The main reason was that patients with preexisting low DBP or high blood pressure amplitude could not be filtered out. Therefore, we developed an index that takes preoperative and postoperative blood pressure amplitudes into consideration to identify 
TABLE 3. Perioperative and midterm results after TAVI stratified by mortality

\begin{tabular}{|c|c|c|c|c|c|c|c|c|}
\hline & \multicolumn{4}{|c|}{ Perioperative results } & \multicolumn{4}{|c|}{ Follow-up results at 1-y } \\
\hline & OR & $\mathbf{9 5} \% \mathbf{C I}$ & $95 \%$ CI & $P$ value & OR & $95 \% \mathrm{CI}$ & $95 \% \mathrm{CI}$ & $P$ value \\
\hline Balloon/self-expandable & 1.072 & 1.018 & 1.129 & .511 & 0.167 & 0.029 & 0.963 & .026 \\
\hline \multicolumn{9}{|l|}{ TAVI } \\
\hline Transapical & 3.488 & 0.646 & 18.828 & .125 & 1.424 & 0.613 & 3.308 & .410 \\
\hline Transfemoral & 0.191 & 0.022 & 1.643 & .096 & 0.526 & 0.219 & 1.263 & .147 \\
\hline Transaxillary & 0.993 & 0.887 & 0.982 & .551 & 12.154 & 1.3 & 113.671 & .007 \\
\hline Transaortic & 2.286 & 0.240 & 21.725 & .460 & 0.360 & 0.042 & 3.053 & .330 \\
\hline Unplanned use of cardiopulmonary bypass & 4.125 & 0.397 & 42.871 & .201 & 1.833 & 0.291 & 11.552 & .513 \\
\hline Valve-in-valve deployment & 0.933 & 0.889 & 0.983 & .647 & 0.720 & 0.639 & 0.810 & .282 \\
\hline $\mathrm{RAI} \geq 14$ & 7.840 & 1.208 & 50.863 & .013 & 7.8 & 1.424 & 42.721 & .007 \\
\hline Major vascular complication & 0.993 & 0.887 & 0.982 & .551 & 0.655 & 0.070 & 6.109 & .709 \\
\hline Stroke & 0.935 & 0.890 & 0.983 & .710 & 0.259 & 0.188 & 0.357 & .02 \\
\hline Perioperative arteriovenous block stage III (new pacemaker) & 0.934 & 0.888 & 0.982 & .595 & 2.786 & 0.374 & 20.728 & .298 \\
\hline Stage 1 AKI & 1.664 & 0.352 & 7.872 & .517 & 1.652 & 0.688 & 3.969 & .259 \\
\hline Stage 2 AKI & 2.347 & 0.417 & 13.221 & .321 & 1.133 & 0.363 & 3.542 & .829 \\
\hline Stage 3 AKI & 5.486 & 0.897 & 33.536 & .052 & 3.8 & 0.946 & 15.261 & .057 \\
\hline Perioperative renal replacement therapy & 1.438 & 1.097 & 1.884 & $<.0001$ & 6.903 & 2.545 & 18.721 & .000047 \\
\hline Perioperative respiratory failure & 26.133 & 4.560 & 149.779 & $<.0001$ & 3.800 & 1.146 & 15.261 & .047 \\
\hline \multicolumn{9}{|l|}{ Paravalvular aortic regurgitation } \\
\hline None or trace & 1.076 & 0.229 & 5.052 & .926 & 0.943 & 0.378 & 2.349 & .899 \\
\hline Mild & 0.297 & 0.034 & 2.565 & .244 & 0.375 & 0.138 & 1.020 & .149 \\
\hline Moderate & 4.75 & 0.792 & 28.494 & .064 & 4.750 & 1.237 & 18.246 & .115 \\
\hline Severe & 0.936 & 0.891 & 0.983 & .793 & 0.266 & 0.195 & 0.363 & .101 \\
\hline$\geq 2+$ & 4.178 & 0.707 & 24.692 & .091 & 5.783 & 1.554 & 21.518 & .004 \\
\hline $\mathrm{sPAP}>60 \mathrm{~mm} \mathrm{Hg}$ & 15.310 & 1.765 & 132.773 & .002 & 3.669 & 1.517 & 8.872 & .003 \\
\hline Previous cardiac surgery & 0.446 & 0.051 & 3.875 & .454 & 0.467 & 0.160 & 1.364 & .158 \\
\hline Previous valvuloplasty & 4.125 & 0.397 & 42.871 & .201 & 1.833 & 0.291 & 11.552 & .513 \\
\hline Atrial fibrillation & 2.590 & 0.549 & 12.223 & .215 & 1.925 & 0.815 & 4.545 & .132 \\
\hline Chronic obstructive pulmonary disease & 1.473 & 0.267 & 8.112 & .655 & 1.455 & 0.547 & 3.865 & .451 \\
\hline Chronic venous insufficiency & 1.021 & 0.187 & 5.560 & .981 & 0.901 & 0.351 & 2.314 & .829 \\
\hline Mitral regurgitation $\geq 2+$ & 1.185 & 0.217 & 6.478 & .845 & 2.146 & 0.859 & 5.360 & .098 \\
\hline Smoking & 0.928 & 0.878 & 0.981 & .317 & 1.8 & 0.539 & 6.015 & .335 \\
\hline Hyperlipidemia & 0.253 & 0.053 & 1.207 & .067 & 0.538 & 0.218 & 1.328 & .176 \\
\hline Arterial hypertension & 0.505 & 0.054 & 4.730 & .543 & 0.433 & 0.108 & 1.737 & .227 \\
\hline Body mass index $\geq 30 \mathrm{~kg} / \mathrm{m}^{2}$ & 1.060 & 0.118 & 1.474 & .959 & 1.4 & 0.436 & 4.496 & .571 \\
\hline Diabetes & 0.911 & 0.851 & 0.976 & .087 & 1.737 & 0.707 & 4.266 & .226 \\
\hline Cerebrovascular accident & 0.921 & 0.867 & 0.979 & .184 & 0.570 & 0.175 & 1.858 & .347 \\
\hline Previous stroke & 0.926 & 0.874 & 0.980 & .259 & 0.872 & 0.258 & 2.948 & .825 \\
\hline Peripheral vascular disease & 0.978 & 0.110 & 8.707 & .984 & 1.750 & 0.575 & 5.327 & .320 \\
\hline Creatinine $\geq 2 \mathrm{mg} / \mathrm{dL}$ & 1.979 & 0.211 & 18.528 & .543 & 3.8 & 0.946 & 15.261 & .057 \\
\hline Dialysis & 0.935 & 0.889 & 0.983 & .647 & 5.643 & 0.492 & 64.667 & .120 \\
\hline History of cancer & 0.914 & 0.854 & 0.977 & .102 & 0.467 & 0.160 & 1.364 & .158 \\
\hline
\end{tabular}

Statistically significant results $(P<.05)$ are in bold. $T A V I$, Transcatheter aortic valve implantation; $O R$, odds ratio; $C I$, confidence interval; $R A I$, relative amplitude index; $A K I$, acute kidney injury; $S P A P$, systolic pulmonary arterial hypertension.

the patients who are more at risk for PAR-associated organ damage. One explanation could be that patients with preexisting aortic regurgitation in addition to aortic stenosis are more likely to compensate for the volume overload resulting from PAR due to the increased left ventricular enddiastolic volume and myocardial hypertrophy. ${ }^{17}$

Another possible approach could be a high preexisting blood pressure amplitude due to the occurrence of vessel wall stiffness associated with atherosclerotic processes. The hypothesis that large artery stiffening is related to a decreased DBP has been postulated in older studies. ${ }^{18} \mathrm{~A}$ high degree of arterial stiffness was found to correlate with increased aortic atherosclerosis and worse clinical outcome in elderly patients. ${ }^{9}$ This extends to a significant association between aortic root/valve calcification scores and the degree of PAR. ${ }^{19}$

Our results confirm the findings of previous investigators that PAR $\geq 2+$ is associated with increased mortality. ${ }^{4,6,20,21}$ According to the GARY investigators, PAR $\geq 2+$ was an independent predictor for perioperative 
mortality after TAVI. ${ }^{22}$ The results of the Italian registry revealed that previous stroke, previous acute pulmonary edema, chronic kidney disease, and PAR $\geq 2+$ were significant predictors of 1-year mortality. ${ }^{23}$ In the UK registry, independent predictors of 1-year mortality were other than transfemoral route, low left ventricular ejection fraction (LVEF), chronic obstructive pulmonary disease, and PAR $\geq 2+{ }^{24}$ Even in follow-up results of patients who underwent conventional surgical AVR, significantly higher mortality rates were observed in those with residual PAR $>1+{ }^{21}$ Common surgical scores such as EuroSCORE I or II and Society of Thoracic Surgeons score are considered to be poor predictors for the outcome after TAVI. ${ }^{25}$

Similar to PAR $\geq 2+$, RAI $\geq 14$ was shown to be a significant independent predictor for long-term mortality in patients after TAVI. According to our hypothesis, blood pressure amplitude, and consequently RAI, increase in the presence of PAR. Moreover, we detected a linear correlation between the severity of PAR and RAI. This finding is supported by the results of Sinning and colleagues, ${ }^{6}$ who described the aortic regurgitation index, based on the gradient between DBP and left ventricular end-diastolic pressure. The investigators of this study found a significant difference in 1-year mortality and acute renal failure between patients with low and high aortic regurgitation index. We also found higher perioperative cardiac and renal complications as possible signs of end-organ failure in patients with $\mathrm{PAR} \geq 2+$ and $\mathrm{RAI} \geq 14$.

From the observation that most deaths occur within 3 months after TAVI, we aimed to further investigate the impact of increased RAI as well as PAR $\geq 2+$ on the midterm outcome after the procedure. The aortic regurgitation index was found to be an independent predictor of 1-year mortality after TAVI using exclusively selfexpandable valves. ${ }^{6}$ In our hands, RAI $\geq 14$ was also associated with a significantly higher midterm mortality. A trend of higher renal and respiratory failure as well as rehospitalization for cardiac reasons but not stroke was observed in these patients. Not surprisingly, the effect of PAR, and consequently increased RAI, is more apparent in the midterm or long-term after TAVI because the long-term consequences of severe aortic regurgitation (such as volume overload, left ventricular dilatation, reduction of the LVEF, and endocarditis) become more evident. For this reason, we consider this index to be an important prognostic factor for mortality and outcome after TAVI. A closer look among patients who died reveals that all patients with both RAI $\geq 14$ and PAR $\geq 2+$ were dead, whereas mortality rates were higher among patients with RAI $\geq 14$ and no significant PAR than for patients with PAR $\geq 2+$ and normal RAI. Thus, RAI can discriminate between prognostically relevant PAR independent from the severity of regurgitation and regardless of the access route. ${ }^{26}$ Moreover, there are still some patients without significant PAR but a pathologic RAI suggesting that other factors influencing hemodynamics may play a role in mortality after TAVI. This is supported by the fact that 3 of 5 patients with RAI $\geq 14$ who died had no PAR. Severe atherosclerosis with increased arterial stiffness and subsequent low diastolic and mean arterial pressure may lead to end-organ hypoperfusion and failure in these patients. Although this is one of the few studies in the literature correlating hemodynamic alterations in patients with PAR after TAVI with perioperative and midterm outcome, it has some limitations. The retrospective design and the low number of patients with PAR in this monocenter study may have led to some bias. However, we present a representative population of TAVI candidates, mainly including patients treated with balloon-expandable valves, with $100 \%$ complete follow-up.

\section{CONCLUSIONS}

Our results demonstrate that RAI is not only a useful tool to predict the hemodynamic effect of PAR after TAVI but is also an independent predictor for midterm mortality. The calculation of this novel index in contrast to preexisting studies is independent from the availability of cardiac ultrasonography or angiography; it is easy to perform (even at the bedside) and is a reproducible and inexpensive method based on 2 simple blood measurements. RAI can be also calculated on an outpatient basis and can be used to follow patients with known PAR. However, the postoperative course of RAI, as well as its impact on the long-term outcome after TAVI, and the correlation to the patterns of valvular and annular calcification $^{27}$ remain unexplored. Possible changes in the index as a result of left ventricular adaptation or optimized medical treatment may be significant factors influencing outcome and can be addressed in further investigations.

\section{References}

1. Bonow RO, Carabello BA, Chatterjee K, de Leon AC, Faxon DP, Freed MD, et al 2008 Focused update incorporated into the ACC/AHA 2006 guidelines for the management of patients with valvular heart disease: a report of the American College of Cardiology/American Heart Association Task Force on Practice Guidelines (Writing Committee to Revise the 1998 Guidelines for the Managemen of Patients With Valvular Heart Disease): endorsed by the Society of Cardiovascular Anesthesiologists, Society for Cardiovascular Angiography and Interventions, and Society of Thoracic Surgeons. Circulation. 2008;118:e523-661.

2. Svensson LG, Tuzcu M, Kapadia S, Blackstone EH, Roselli EE, Gillinov AM, et al. A comprehensive review of the PARTNER trial. J Thorac Cardiovasc Surg. 2013;145(3 Suppl):S11-6.

3. Unbehaun A, Pasic M, Dreysse S, Drews T, Kukucka M, Mladenow A, et al Transapical aortic valve implantation: incidence and predictors of paravalvular leakage and transvalvular regurgitation in a series of 358 patients. J Am Coll Cardiol. 2012;59:211-21.

4. Hayashida K, Lefèvre T, Chevalier B, Hovasse T, Romano M, Garot P, et al Impact of post-procedural aortic regurgitation on mortality after transcatheter aortic valve implantation. JACC Cardiovasc Interv. 2012;5:1247-56.

5. Kodali SK, Williams MR, Smith CR, Svensson LG, Webb JG, Makkar RR, et al. Two-year outcomes after transcatheter or surgical aortic-valve replacement. $N$ Engl J Med. 2012;366:1686-95.

6. Sinning JM, Hammerstingl C, Vasa-Nicotera M, Adenauer V, Lema Cachiguango SJ, Scheer AC, et al. Aortic regurgitation index defines severity of peri-prosthetic regurgitation and predicts outcome in patients after transcatheter aortic valve implantation. J Am Coll Cardiol. 2012;59:1134-41. 
7. Noble S, Roffi M. Pressure curve measurements during transcatheter aortic valve implantation: a useful tool to assess the severity of aortic regurgitation. Ann Thorac Surg. 2013;95:e21.

8. Gotzmann M, Lindstaedt M, Mügge A. From pressure overload to volume overload: aortic regurgitation after transcatheter aortic valve implantation. Am Heart J. 2012;163:903-11.

9. Witteman JC, Grobbee DE, Valkenburg HA, van Hemert AM, Stijnen T, Burger $\mathrm{H}$, et al. J-shaped relation between change in diastolic blood pressure and progression of aortic atherosclerosis. Lancet. 1994;343:504-7.

10. Kappetein AP, Head SJ, Généreux P, Piazza N, van Mieghem NM, Blackstone EH, et al. Updated standardized endpoint definitions for transcatheter aortic valve implantation: the Valve Academic Research Consortium-2 consensus document. J Thorac Cardiovasc Surg. 2013;145:6-23.

11. Lancellotti P, Tribouilloy C, Hagendorff A, Moura L, Popescu BA, Agricola E, et al. European Association of Echocardiography recommendations for the assessment of valvular regurgitation. Part 1: aortic and pulmonary regurgitation (native valve disease). Eur J Echocardiogr. 2010;11:223-44.

12. Bleiziffer S, Mazzitelli D, Opitz A, Hettich I, Ruge H, Piazza N, et al. Beyond the short-term: clinical outcome and valve performance 2 years after transcatheter aortic valve implantation in 227 patients. J Thorac Cardiovasc Surg. 2012;143: 310-7.

13. Conradi L, Seiffert M, Treede H, Silaschi M, Baldus S, Schirmer J, et al. Transcatheter aortic valve implantation versus surgical aortic valve replacement: a propensity score analysis in patients at high surgical risk. J Thorac Cardiovasc Surg. 2012;143:64-71.

14. Wilbring M, Tugtekin SM, Alexiou K, Simonis G, Matschke K, Kappert U. Transapical transcatheter aortic valve implantation vs conventional aortic valve replacement in high-risk patients with previous cardiac surgery: a propensityscore analysis. Eur J Cardiothorac Surg. 2013;44:42-7.

15. Bapat V, Attia R, Redwood S, Hancock J, Wilson K, Young C, et al. Use of transcatheter heart valves for a valve-in-valve implantation in patients with degenerated aortic bioprosthesis: technical considerations and results. J Thorac Cardiovasc Surg. 2012;144:1372-9; discussion 1379-80.

16. Bekeredjian R, Grayburn PA. Valvular heart disease: aortic regurgitation. Circulation. 2005;112:125-34.

17. Goldbarg SH, Halperin JL. Aortic regurgitation: disease progression and management. Nat Clin Pract Cardiovasc Med. 2008;5:269-79.

18. Sleight P. Blood pressures, hearts, and U-shaped curves. Lancet. 1988;1:235.

19. Koos R, Mahnken AH, Dohmen G, Brehmer K, Günther RW, Autschbach R, et al. Association of aortic valve calcification severity with the degree of aortic regurgitation after transcatheter aortic valve implantation. Int J Cardiol. 2011;150:142-5.

20. Toggweiler S, Humphries KH, Lee M, Binder RK, Moss RR, Freeman M, et al 5-year outcome after transcatheter aortic valve implantation. J Am Coll Cardiol. 2013;61:413-9.

21. Sponga S, Perron J, Dagenais F, Mohammadi S, Baillot R, Doyle D, et al. Impact of residual regurgitation after aortic valve replacement. Eur J Cardiothorac Surg. 2012;42:486-92.

22. Zahn R, Gerckens U, Linke A, Sievert H, Kahlert P, Hambrecht R, et al. Predictors of one-year mortality after transcatheter aortic valve implantation for severe symptomatic aortic stenosis. Am J Cardiol. 2013;112:272-9.

23. Tamburino C, Capodanno D, Ramondo A, Petronio AS, Ettori F, Santoro G, et al. Incidence and predictors of early and late mortality after transcatheter aortic valve implantation in 663 patients with severe aortic stenosis. Circulation. 2011;123:299-308.

24. Moat NE, Ludman P, de Belder MA, Bridgewater B, Cunningham AD, Young CP, et al. Long-term outcomes after transcatheter aortic valve implantation in high-risk patients with severe aortic stenosis: the U.K. TAVI (United Kingdom Transcatheter Aortic Valve Implantation) Registry. J Am Coll Cardiol. 2011;58:2130-8.

25. Barili F, Pacini D, Capo A, Ardemagni E, Pellicciari G, Zanobini M, et al. Reliability of new scores in predicting perioperative mortality after isolated aortic valve surgery: a comparison with the society of thoracic surgeons score and logistic EuroSCORE. Ann Thorac Surg. 2013;95:1539-44.

26. Bonaros N, Bartel T, Friedrich G, Mueller S, Feuchtner G, Schachner T, et al. Transcatheter aortic valve implantation via transaortic access: a bail-out strategy in unexpectedly inoperable patients. Eur Surg. 2012;44:416-8.

27. Feuchtner G, Plank F, Mueller S, Leipsic J, Schachner T, Mueller L, et al. Prediction of paravalvular regurgitation after transcatheter aortic valve implantation by computed tomography: value of aortic valve and annular calcification. Ann Thorac Surg. 2013;96:1574-80.

\section{Discussion}

Dr Rakesh M. Suri (Rochester, Minn). I would like to thank the Association for the privilege of discussing this paper. By way of disclosure, I am the principal investigator for the FDA IDE trial of the Sorin PERCEVAL valve, but I have no disclosures related to this discussion. I would like to thank Dr Bonaros for sending me a copy of his manuscript in advance.

Dr Bonaros and his colleagues present a study aiming to evaluate the impact of paravalvular leakage, PVL, on hemodynamics and outcome using the relative amplitude index. The authors used ROC analysis to determine that a cut-off point of 14 was associated with increased perioperative respiratory failure, acute renal injury, mortality, and cardiac and renal complications. Interestingly, however, amplitude index and PVL were both found to be independent predictors of mortality at one year.

This is an innovative attempt at developing a simplified hemodynamic parameter to ascertain the degree of periprosthetic regurgitation after TAVR. We recall the recently published Sinning aortic regurgitation index that Dr Bonaros has alluded to today, calculated according to the formula he also described.

That study, too, utilized ROC analysis delineating an index of less than 25 as important in predicting increased one-year mortality compared with those with an index of greater than 25 . The Sinning index also provided additional prognostic information beyond echocardiographically assessed severity of PVL.

Now, both of these mathematical formulae are so-called simple bedside assessments of PVL and may potentially facilitate decisions regarding the need for further balloon dilation of the prosthesis or perhaps TAVR-in-TAVR procedures to ameliorate periprosthetic leak in the operating room.

However, the numbers are small in both studies, so we are mindful of the fact that this may limit the statistical robustness of the proposed relationship between the relative amplitude index (RAI) and the aforementioned end points.

Three simple questions, Dr Bonaros. The first, you alluded to this briefly, but can you please describe what you feel is the true benefit of this new index versus the Sinning index?

Second, the audience would benefit from a description of how your method might be influenced by alterations in ventricular load, and particularly, how it might be affected by either a hypertrophied ventricle that is poorly compliant and less likely to tolerate acute aortic insufficiency versus one preconditioned by the preoperative volume overload associated with significant preexistent regurgitation.

And, finally, could Dr Bonaros postulate why the RAI and PVL in the current analysis were independent predictors of death considering they are presumably related.

I would like to congratulate Dr Bonaros for an excellent presentation and thank the Association for the privilege of discussing this important work.

Dr Bonaros. Thank you, Dr Suri, for the excellent remarks. Just brief answers to your questions.

Number one, the differences between the Sinning index and our index; I think that both series have a series sample of a little bit more than 100 patients. I think the Bonow group had 140 patients. We had 110. 
The difference is that we just use simple blood pressure measurements. This is a decision you reballoon this valve or even to do a valve-in-valve. But, of course, it is a decision whereby you can adjust your medical therapy for those patients to reduce the afterload after the procedure on the ward or even ambulatory. This is the first thing. And, of course, you don't need any invasive measurement with a catheter in the left ventricle or even echocardiography.

For your second question, I agree with you that there is a very huge difference if the patients had preexisting regurgitation or this regurgitation happens acutely. So patients with preexisting regurgitation, in other words with a pure aortic stenosis, who do then have periprosthetic regurgitation, they would probably have an impaired outcome. This is the major hypothesis of this study.

There was a very good article two years ago in American Heart Journal entitled "Paravalvular Leakage from Pressure Overload to Volume Overload." So in this case, we have a volume overload in the left ventricle, and this ventricle is not able to compensate for this overload. So there should be some truth in this postulation.

For your third question, we were also surprised to see that both the index and the paravalvular regurgitation were independent predictors. I, frankly, do not know the answer to the question. I can only hypothesize that by using the frame of the valve in the aortic annulus, we change the geometry of the annulus, and of course we change the compliance of the aortic root. So probably some part of this so-called windkessel function of the aortic root is not available anymore.

So probably there should be some correlation there, too, and the question is what happens? What is the difference between the two valve groups we have available for TAVI if a balloonexpandable valve reacts in a different way than a self-expandable valve.

Dr Lyle D. Joyce (Rochester, Minn). Are you using this to change your practice as yet?

Dr Bonaros. To be honest, we have now started to take it into consideration because we have now finished the evaluation. Again, the numbers are limited. But we have started to take it into consideration. The example I brought was the last patient we did last week. We did take the RAI into consideration, yes.

Dr Joyce. Great. Thank you. Very nice presentation.

Dr Joseph J. Rubelowsky (Hattiesburg, Miss). When you calculated your index, you got a preoperative value, and you subtracted it from your postoperative value. Was there any preoperative regurgitation, and would that influence what your index would be as your final result?

Let's say if you had aortic stenosis with a one- or two-plus aortic regurgitation to begin with, and then you ended up with no aortic stenosis and maybe one-plus paravalvular leak, would that influence what your index would be, I mean, when you predicted at the end?

Dr Bonaros. You are absolutely right. So if you have preexisting regurgitation, the subtrahend of the formula, is going to be high.

So if the patient had a preexisting regurgitation grade 3 and ends up a grade 2, he has an improved index. You are absolutely right. But, fortunately, it was just two patients, so this would not affect our results. That is a good point. 


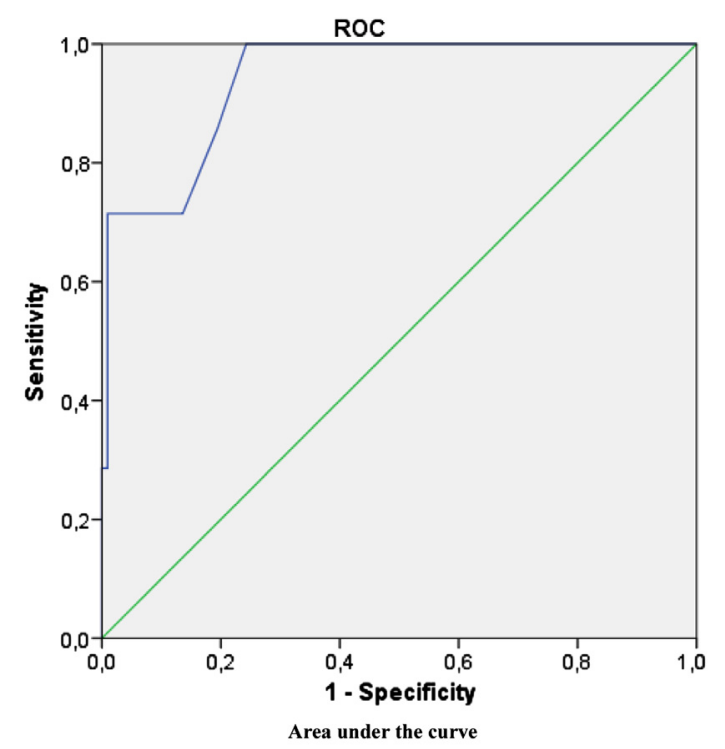

\begin{tabular}{|c|c|c|c|c|}
\hline \multirow[t]{2}{*}{ Area } & \multirow[t]{2}{*}{ Standard error } & \multirow[t]{2}{*}{$\mathrm{p}$-value } & \multicolumn{2}{|c|}{$95 \% \mathrm{CI}$} \\
\hline & & & Lower & Higher \\
\hline ,941 & ,035 & ,000 & ,872 & 1,000 \\
\hline
\end{tabular}

FIGURE E1. Receiver operating characteristics $(R O C)$ for relative amplitude index (RAI) as predictor of 30-day mortality. CI, Confidence interval. 

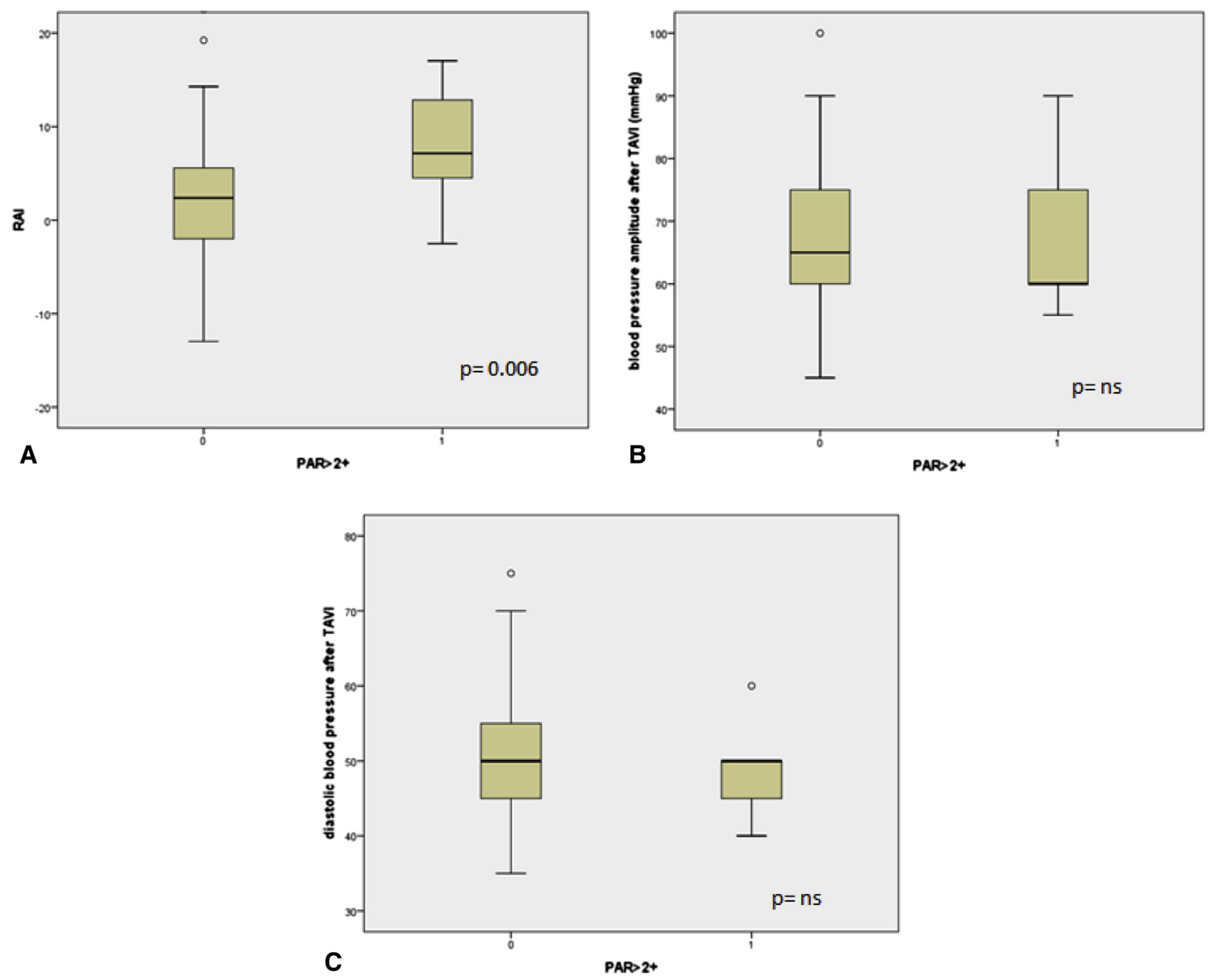

FIGURE E2. Correlations between (A) RAI and PAR; (B) blood pressure amplitude (BPA) and PAR; and (C) diastolic blood pressure (DBP) and PAR. RAI, Relative amplitude index; PAR, paravalvular aortic regurgitation; TAVI, transcatheter aortic valve implantation. 